\title{
PEMANFAATAN DRONE DJI PHANTOM 4 UNTUK IDENTIFIKASI BATAS ADMINISTRASI WILAYAH
}

\author{
Ayu Suciani ${ }^{1}$, M Taufik Rahmadi ${ }^{2}$ \\ 1Program Studi Pendidikan Geografi, Fakultas Keguruan dan Ilmu Pendidikan, UNSAM \\ Jalan Meurandeh, Langsa Lama, Kota Langsa, 24354, Aceh, Indonesia \\ 2 Jurusan Pendidikan Geografi, Fakultas Ilmu Sosial, UNIMED \\ Jalan Willem Iskandar Pasar V Medan Estate, 20221, Indonesia \\ email: ayusuciani@unsam.ac.id
}

Diterima: 6 September 2018; Direvisi: 24 Januari 2019; Disetujui: 14 Juni 2019

\begin{abstract}
Abstrak
Pemanfaatan UAV (Unmanned Aerial Vehicle) atau drone hingga saat ini telah banyak digunakan antara lain untuk monitoring tata ruang kota, identifikasi perubahan lingkungan, konstruksi bangunan, industri, pemetaan perikanan, lahan, kehutanan, tata ruang, hingga pemetaan batas wilayah administrasi. Batas wilayah administrasi merupakan batas atau garis khayal yang hanya terdapat pada peta dan tidak ada di lapangan sesuai dengan ketentuan hukum yang berlaku. Penelitian ini bertujuan untuk menguji tingkat ketelitian hasil foto drone untuk batas administrasi wilayah. Penelitian ini menggunakan metode interpretasi manual. Penelitian ini dilakukan di sebagian wilayah administratif Kota Langsa, yaitu Kelurahan Sidodadi, Kelurahan Serambi, dan Kelurahan Mulia. Pemilihan wilayah kajian ini disebabkan oleh beberapa faktor seperti kepadatan permukiman, pertumbuhan pembangunan yang cepat, dan tingkat kepadatan penduduk yang tinggi. Foto udara perekaman drone pada penelitian ini memiliki resolusi spasial 0.5 meter, sehingga memberikan kenampakan objek yang jelas dan detail.
\end{abstract}

Kata Kunci: Pemetaan, Administrasi, Drone DJI Phantom 4

\begin{abstract}
Utilization of UAV (Unmanned Aerial Vehicle) or drone has been widely used in urban spatial monitoring, identification of environmental changes, building construction, industry, fishery mapping, land, forestry, spatial planning, and mapping administrative boundaries. The administrative boundary is an imaginary line that only available in the map but not exactly exist on earth based on applicable law. The aim of this study is to examine the accuracy of the photo result of the DJI Phantom 4 for regional administrative boundaries. This study uses manual interpretation methods. This research was conducted in some villages of Langsa City, they are; Sidodadi, Serambi, and Mulia. The region selection is based on several factors such as settlement density, rapid development growth, and high population. The aerial photos of drone recording in this study has a spatial resolution 0.5 meters, so that give the clear appearance and detailed object.
\end{abstract}

Keyword: Mapping, Administration, Drone DJI Phantom 4

\section{PENDAHULUAN}

Saat ini pemerintah Indonesia sedang melaksanakan kebijakan satu peta (One Map Policy) sesuai dengan amanat Undang-Undang Nomor 4 Tahun 2011 tentang informasi geospasial dimana semua peta harus merujuk pada Badan Informasi Geospasial (BIG) yang memiliki kedudukan hukum yang tetap. Undangundang tentang informasi geospasial 
dibuat dikarenakan banyaknya terjadi tumpang tindih antar berbagai peta sehingga menimbulkan konflik di masyarakat dan tidak ada dasar hukum pada suatu peta. Dengan diberlakukannya undang-undang informasi geospasial, maka peta memiliki dasar hukum dan memiliki acuan yang tetap.

Untuk mendukung keberhasilan kebijakan satu peta (One Map Policy) maka harus didukung oleh semua lapisan. Kebijakan satu peta harus mendapat dukungan dari semua lapisan pemerintah dan masyarakat. Salah satu teknologi yang saat ini sedang berkembang untuk pemetaan dengan skala besar adalah penggunaan UAV atau drone. Saat ini perkembangan teknologi pemetaan menggunakan pesawat UAV/drone sangatlah pesat, dengan berbagai macam tipe dan spesifikasi. Menurut Suroso (2016) drone merupakan pesawat tanpa awak yang dikendalikan dari jarah jauh oleh auto pilot atau mampu mengendalikan dirinya sendiri dan menggunakan hukum aerodinamika untuk menganggkat diri sendiri agar bisa melakukan penerbangan. UAV atau drone memiliki kemampuan melakukan pelacakan posisi dan arah dari sensor yang dapat diterapkan dalam sistem kordinat global dan koordinat lokal (Eisenbeiss, 2009 dalam Utomo, 2017).

UAV atau drone memiliki keunggulan dibandingkan dengan citra satelit antara lain dapat dioperasikan relatif cepat dan berulang, mampu terbang rendah sehingga menghasilkan citra resolusi tinggi, biaya lebih rendah, aplikasi yang beragam, dan tanpa menggunakan pilot, sedangkan citra satelit waktu perekamannya sudah ditetapkan, adanya gangguan awan, dan gangguan-gangguan lain saat perekaman (Shofiyanti, 2011). Menurut Zaco, et al, (2014) dalam Utomo (2017) penggunaan drone akan menghasilkan gambaran kenampakan bumi dengan resolusi spasial tinggi dan tidak terkendala awan, sehingga proses pengumpulan datanya menjadi lebih mudah.
Pemanfaatan UAV/drone hingga saat ini telah banyak dilakukan antara lain monitoring tata ruang kota, melihat kawasan hutan, perhitungan jumlah pokok tanaman, identifikasi perubahan lingkungan, konstruksi bangunan, industri, pemetaan perikanan, lahan, kehutanan, tata ruang, hingga pemetaan batas wilayah administrasi daerah/kota. Penegasan atau penetapan batas administrasi haruslah dimulai dari unit terkecil yaitu desa/kelurahan, kecamatan, kabupaten/kota, dan provinsi, hal ini bertujuan agar perencanaan dan pembangunan wilayah dapat berjalan dengan baik, sesuai dengan UndangUndang No 23 Tahun 2014. Saat ini foto udara menggunakan drone banyak digunakan untuk memetakan suatu wilayah administrasi, hal ini dikarenakan foto udara (drone) dapat merekam wilayah administrasi kapan pun, tanpa terikat waktu seperti citra satelit, dan menghasilkan resolusi yang tinggi.

Menurut Peraturan Menteri Dalam Negeri Nomor 76 Tahun 2012 tentang pedoman penegasan batas daerah, batas daerah adalah kumpulan titik-titik koordinat geografis yang merujuk kepada sistem georeferensi nasional dan membentuk garis batas wilayah administrasi pemerintahan antardaerah. Budisusanto et al., (2014) mengemukakan batas wilayah memiliki fungsi yang sangat penting antara lain meminimalisasi terjadinya konflik batas, sebagai rujukan kerja yang akan datang, tertib administrasi pemerintahan, perhitungan fiskal daerah, kepastian hukum dan yurisdiksi pemerintah daerah, dan rencana tata ruang tepat sasaran. Hingga saat ini batas wilayah administrasi masih menjadi masalah karena belum semua wilayah administratif memiliki batas segmen yang tegas dan jelas, yang ditandai dengan banyaknya permasalahkan yang timbul baik secara pemerintahan hingga konflik antarmasyarakat.

Adapun tujuan penelitian ini adalah untuk menguji tingkat ketelitian drone DJI 
Phantom 4 dalam memetakan batas administrasi wilayah di sebagaian Kota Langsa.

\section{METODE PENELITIAN \\ Lokasi Penelitian}

Penelitian ini dilakukan di sebagian wilayah administratif Kota Langsa, yaitu Kelurahan Sidodadi, Kelurahan Serambi, dan Kelurahan Mulia. Pemilihan wilayah kajian ini tidak terlalu besar disebabkan oleh beberapa faktor seperti kepadatan permukiman, pertumbuhan pembangunan yang cepat, dan tingkat kepadatan penduduk yang tinggi. Selain itu, Kota Langsa merupakan wilayah yang membutuhkan peta sebagai bagian dari perencanaan tata ruang dan wilayah sehingga memudahkan sistem administrasi pemerintah untuk memperjelas batas antar wilayah administrasi mulai dari tingkat kelurahan hingga tingkat kecamatan, sehingga sesuai dengan undang-undang yang telat ditetapkan, dan dapat mendukung kebijakan satu peta.

Kota langsa mempunyai luas wilayah $261,41 \mathrm{~km}^{2}$ yang terletak pada posisi antara $04^{\circ} 24^{\prime} 35,68^{\prime \prime}-04^{\circ} 33^{\prime} 47,03^{\prime \prime}$ LU dan $97^{\circ} 53^{\prime} 14,59^{\prime \prime}-98^{\circ} 04^{\prime} 42,16^{\prime \prime}$ BT, dengan ketinggian antara 0-25 mdpl. Kota terdiri atas 5 kecamatan dan 66 gampong/kelurahan.

\section{Data Penelitian}

Penelitian ini menggunakan beberapa data antara lain:
1. Foto udara hasil perekaman DJI Phantom 4

2. Peta RBI Lembar Kota Langsa (062014)

\section{Peralatan Penelitian}

Peralatan yang digunakan dalam penelitian ini antara lain:

1. Drone DJI Phantom 4 untuk perekaman foto udara;

2. Software Agisoft Photoscan Professional untuk penggabungan foto udara hasil perekaman;

3. Softwar ArcGIS 10.4 untuk koreksi geometrik dan visualisasi foto udara;

4. Laptop Asus A450L untuk pengolahan data; dan

5. Smartphone untuk tampilan drone dalam pembuatan jalur terbang, kalibrasi, dan proses perekaman.

\section{Pemrosesan Data}

Pemrosesan data merupakan proses mendapatkan dan pembetulan data (foto udara) agar foto udara dapat digunakan dan memberikan informasi yang akurat, sehingga dapat diolah dengan data-data lainnya untuk mendukung jalannya penelitian. tahapan yang dilakukan dalam pemrosesan data pada penelitian ini terdiri atas pembuatan jalur terbang, kalibrasi wahana drone, masking data, dan koreksi geometrik. Untuk lebih jelaskan tahapan pemrosesan data dapat dilihat pada Gambar 1 berikut ini.

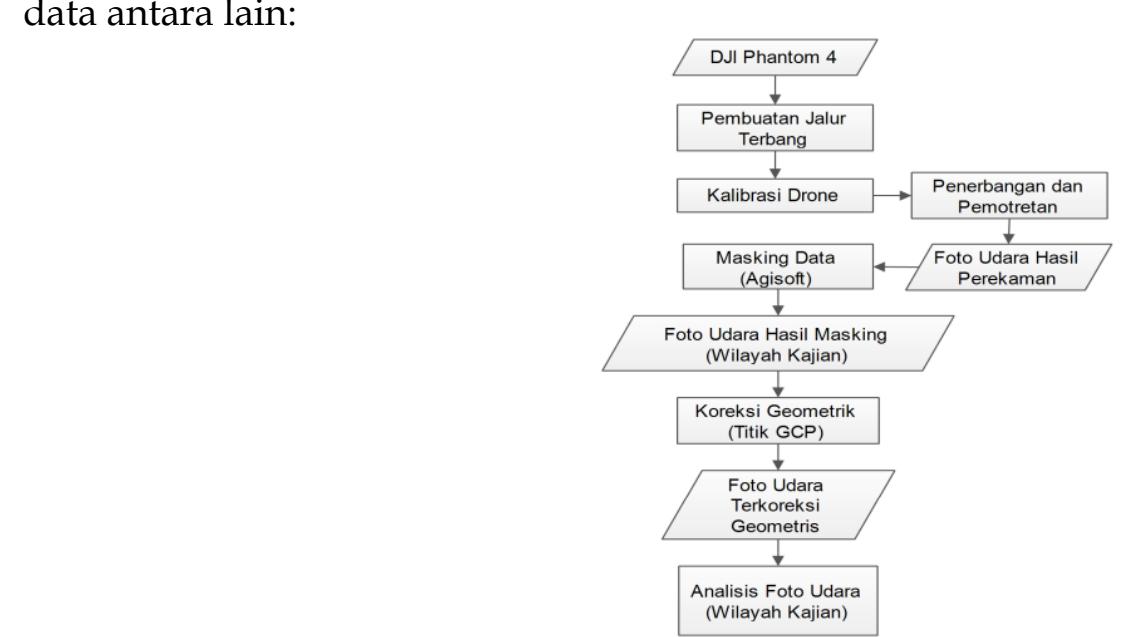

Gambar 1. Tahapan Pemrosesan Data Drone 


\section{HASIL DAN PEMBAHASAN}

Berdasarkan hasil pemotretan udara menggunakan drone DJI Phantom 4 pada ketinggian terbang $150 \mathrm{mdpl}$, drone DJI Phantom 4 menghasilkan gambar permukaan bumi/wilayah dengan resolusi spasial 0,5 meter. Identifikasi dan analisis batas administrasi dapat dilakukan dengan interpretasi secara manual, hal ini karena foto udara hasil perekaman drone DJI Phantom 4 memberikan kenampakan objek-objek yang cukup jelas dan detail, sehingga dapat membedakan kenampakan objek unsur alam dan unsur buatan manusia dengan mudah.
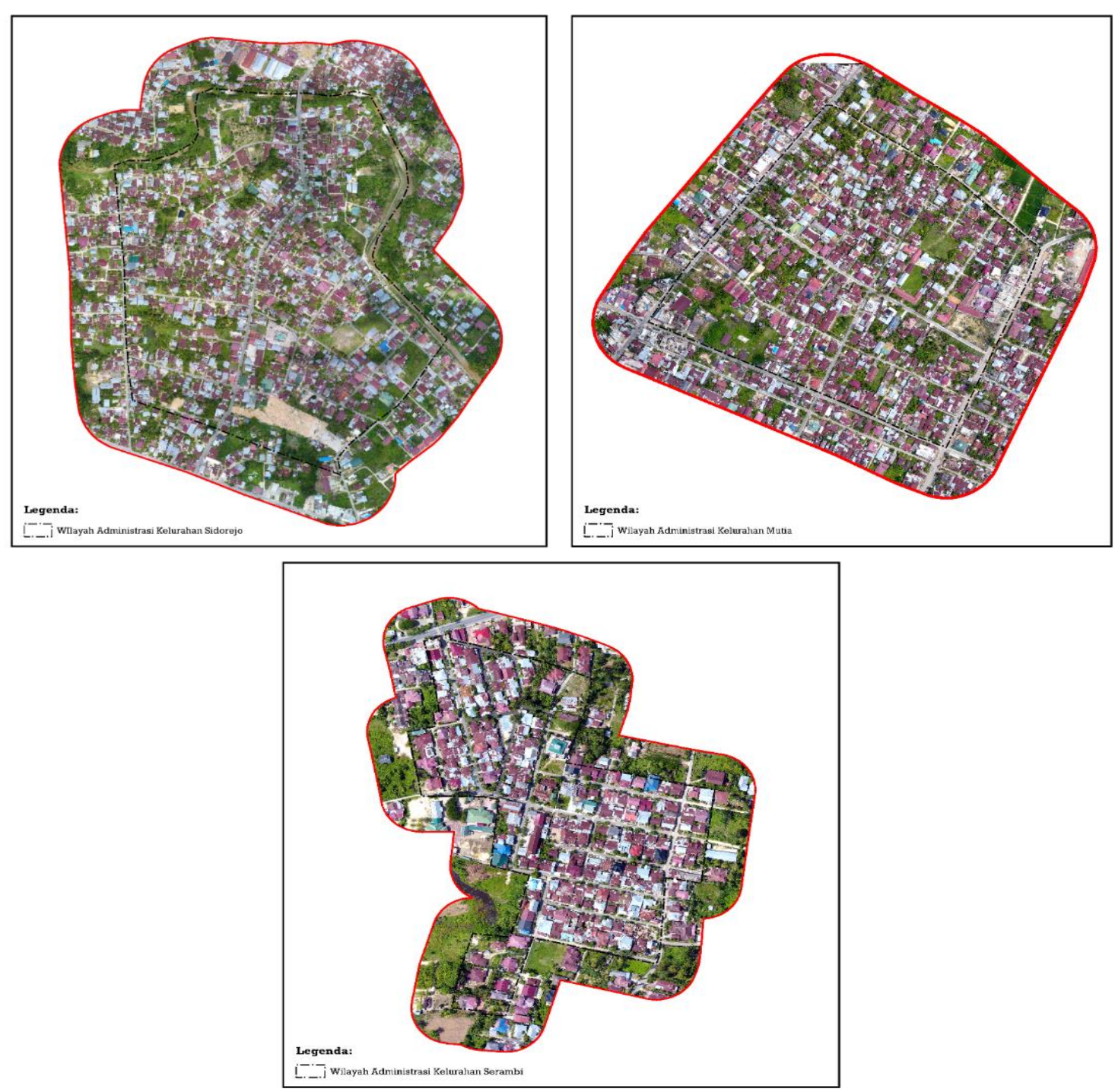

Gambar 2. Foro Udara Hasil Perekaman Negeri Nomor 76 Tahun 2012 Tentang Pedoman Penegasan Batas Daerah, batas daerah di darat adalah pembatas wilayah administrasi pemerintahan antar daerah yang merupakan rangkaian titik-titik koordinat yang berada pada permukaan bumi dapat berupa tanda alam seperti igir/punggung gunung, median sungai dan/atau unsur buatan di lapangan yang dituangkan dalam bentuk peta (garis khayal yang hanya terdapat dipeta dan tidak ada di lapangan). Untuk lebih jelasnya hasil foto udara menggunakan drone DJI Phantom 4 dapat dilihat pada Gambar 2 berikut ini. 
Berdasarkan Gambar 2 dapat dilihat kenampakan batas wilayah administrasi Kelurahan Sidorejo terdiri atas unsur alam yaitu median sungai dan unsur buatan manusia yaitu median jalan. Kelurahan Serambi dan Mutia memiliki batas wilayah berupa unsur buatan manusia yaitu media jalan dan tidak adanya sedikitpun unsur alam. Pada sebagian wilayah Kelurahan Sidorejo dan Serambi batas administrasi wilayah tidak diikuti oleh unsur alam dan unsur buatan yang artinya tidak sesuai dengan kaidah kartografis, yaitu batas wilayah administrasi terletak pada lahan kosong dan memotong sebagian rumah penduduk. Penegasan batas wilayah administrasi yang tidak sesuai dengan kaidah kartografis, undang-undang, dan peraturan menteri dalam negeri biasanya terjadi karena adanya persepsi yang salah di masyarakat, mereka beranggapan bahwa penegasan batas administrasi atau mengubah batas administrasi yang sudah ada mengikuti unsur alam atau unsur buatan manusia sama dengan mengusir atau mengambil tanah yang mereka tempati, sehingga sebagian wilayah administrasi tidak memiliki batas yang jelas antara satu kelurahan dengan kelurahan lainnya.

Pemetaan identifikasi batas wilayah administrasi menggunakan drone DJI Phantom 4 dapat digunakan pada wilayah yang tidak terlalu besar sehingga tidak memerlukan waktu yang lama dalam proses pemetaannya. Pemetaan batas wilayah administrasi menggunakan drone memberikan keuntungan yang lebih efektif diantaranya dapat melakukan perekaman kapanpun sesuai dengan keinginan pengguna; menyajikan informasi secara aktual dan faktual; menghemat biaya; dan dapat dimengerti oleh orang yang tidak mengerti/tidak paham citra satelit.

Menurut Purnomo (2017) sebelum melakukan identifikasi penegasan batas wilayah administrasi menggunakan foto udara ataupun citra satelit, terdapat beberapa tahapan yang harus dilakukan yaitu sosialisasi; membentuk tim; melakukan musyawarah dengan perangkat desa/kelurahan/kecamatan; membuat sketsa wilayah administrasi; melakukan tracking GPS batas wilayah administrasi; membuat peta menggunakan Arc GIS hasil tracking GPS; melakukan penerbangan drone (perekaman wilayah); mosaik (penggabungan) hasil perekaman drone; dan sosialisasi hasil penegasan batas wilayah administrasi menggunakan drone.

Pemetaan batas wilayah administrasi menggunakan drone memiliki kekurangan yaitu membutuhkan waktu yang lama dalam perekaman wilayah yang luas. DJI Phantom 4 sendiri dilengkapi dengan empat baterai dan masing-masing baterai dapat terbang selama 15 menit dalam jangkauan maksimal $5 \mathrm{~km}^{2}$ sehingga dengan empat baterai drone dapat terbang selama 60 menit dengan total luas wilayah yang direkam meliputi $20 \mathrm{~km}^{2}$ wilayah setiap penerbangan. Hal ini merupakan suatu kekurangan bila dibandingkan dengan citra satelit yang bisa merekam suatu wilayah luas hanya dengan sekali perekaman.

\section{KESIMPULAN}

Berdasarkan hasil penelitian dapat disimpulan bahwa foto udara hasil perekaman drone DJI Phantom 4 untuk pemetaan identifikasi batas administrasi memiliki beberapa keuntungan yaitu menghasilkan resolusi foto udara yang tinggi dan dapat dipahami oleh semua pihak yang terlibat dalam penegasan batas administrasi. Pemetaan identifikasi batas administrasi memerlukan kajian lebih lanjut mengingat diperlukan waktu yang lama untuk mendapatkan foto udara dengan wilayah yang luas. Penggunaan wahana drone lebih direkomendasikan sebagai alat pemantauan suatu wilayah berdasarkan data yang sudah ada. 


\section{DAFTAR PUSTAKA}

Budisusanto, Y., Khomsin., Purwati, R., Nurry, A., \& Widiastuty, R. (2014). Pemetaan Partisipatif Batas Kelurahan di Kecamatan Sukolilo Kota Surabaya.Jurusan Teknik Geomatika FTSP-ITS. GEOID Vol.10, No. 01. pp 87-92.

Https://www.liupurnomo.com. Alur Pemetaan Batas Desa Mengunakan Drone (diakses tanggal 10 Mei 2018 Pukul 10.00).

Http://www.big.go.id/ Pemetaan Batas Wilayah Untuk Penataan Wilayah Bukan Pembagian Kekuasaan (diakses (diakses tanggal 10 Mei 2018 Pukul 10.00).

Peraturan Menteri Dalam Negeri Republik Indonesia Nomor 76 Tahun 2012 Tentang Pedoman Penegasan Batas Daerah.
Shofiyati, Rizatun. (2011). Teknologi Pesawat Tanpa Awak Untuk Pemetaan dan Pemantauan Tanaman dan Lahan Pertanian. Informatika Pertanian. Vol. 20 No. 02. pp. 58-64.

Suroso, Indreswari. (2016). Peran Drone/Unmanned Aerial Vehicle (UAV) Buatan STTKD Dalam Dunia Penerbangan. Program Studi Teknik Aeronautika, Sekolah Tinggi Teknologi Kedirgantaraan.

Undang-Undang Nomor 4 Tahun 2011 Tentang Informasi Geospasial

Undang-Undang Nomor 23 Tahun 2014 Tentang Pemerintahan Daerah.

Utomo, Budi. (2017). Drone Untuk Percepatan Pemetaan Bidang Tanah. Media Komunikasi Geografi. Vol. 18. No.02. pp. 146-15. 